\title{
Treatment of conjunctivitis
}

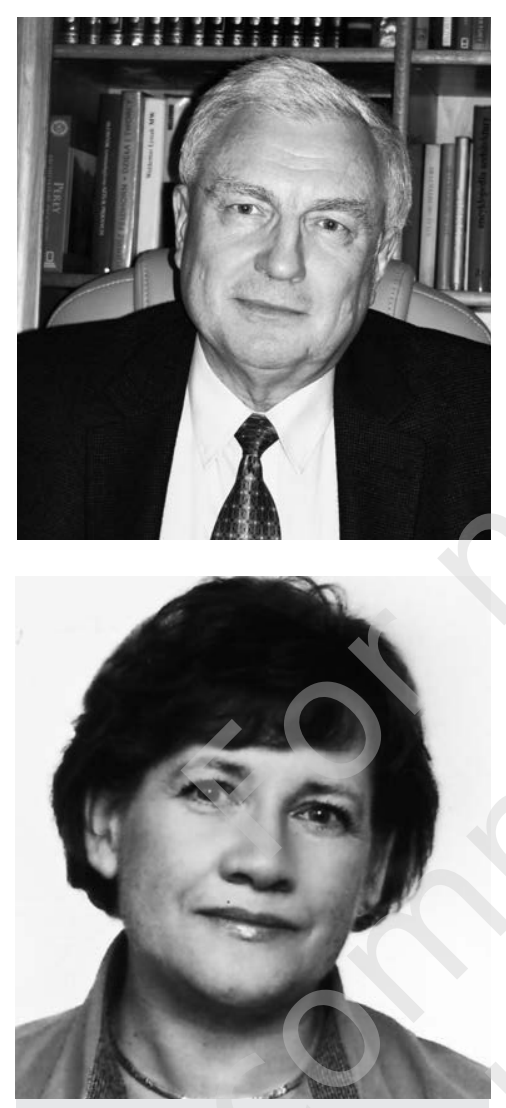

\section{Marek E. Prost ${ }^{1}$, Beata Rymgayłło-Jankowska ${ }^{2}$}

${ }^{1}$ Department of Ophthalmology, Military Institute of Aviation Medicine, Warsaw Head: Radosław Różycki, MD, PhD

${ }^{2}$ Department of Diagnostic and Microsurgery of Glaucoma, Chair of Ophthalmology, Medical University of Lublin Head: Prof. Tomasz Żarnowski, MD, PhD

\section{ABSTRACT}

The aim of the publication is to present a description of a few clinical cases of conjunctivitis, in which treatment with the use of ophthalmic preparations that have existed for a long time has proved to be an effective form of therapy.

Key words: conjunctivits, treatment, antibiotics 


\section{INTRODUCTION}

The last few decades witnessed a very rapid development and scientific progress in the field of biotechnology and medicine, which resulted in the introduction of new, often innovative drugs to the market. This is also the case in the treatment of eye diseases, primarily in the treatment of glaucoma and age-related macular degeneration. Does this mean that older drugs should no longer be used? The progress in the treatment of conjunctival and corneal diseases is not as fast as in the above-mentioned sections of ophthalmology, and many of the preparations available on the market have retained their therapeutic effectiveness, especially since pharmaceutical companies have not recently developed new combined drugs (e.g. antibiotics and glucocorticosteroids) or new eye medications in the form of suspensions and ointments.

The authors of this study would like to present several clinical cases in which treatment with the use of long-established ophthalmic preparations has proved to be an effective form of therapy.

\section{CASE STUDIES}

\section{Case study 1}

A 40-year-old female patient presented to the ophthalmologist's office with discomfort, constant foreign body sensation in both eyes and their irritation. The symptoms were accompanied by itching and quite massive edema of the conjunctiva and eyelid margins. The patient also complained of moderate photophobia and resulting in the eyelids sticking together in the morning on awaking - the symptoms were of similar intensity bilaterally. The symptoms had lasted for approx. 3-4 weeks and made it difficult for the patient to perform daily activities, and above all, they made it impossible to perform her job as an elementary teacher, i.e. work with children requiring commitment and concentration, including work with computers. Initially, the patient took antibiotic drops prescribed by a GP, but after taking the medication she did not notice any improvement and discontinued treatment after about a week. After a few more days, the pruritus, discomfort and foreign body sensation and irritation of the eyelid margins increased further.

On ophthalmologic examination, marked edema of the conjunctiva (eyeball and lid conjunctivae) and the presence of a large amount of watery-mucous discharge in the conjunctival sac of both eyes were observed. In addition, severe redness and swelling of the eyelid margins along with swelling of the lower and upper lacrimal punctum were observed. The cornea, anterior chamber and lens showed no abnormalities, as did the posterior segment of the eye.
The patient had experienced similar symptoms on several occasions in the past, but they were never as severe as at present and usually resolved after a very short time. The reported, as well as the results of the ophthalmologic examination - eyeball itching, conjunctival edema, the presence of a large amount of mucous-water discharge and moderate photophobia, eyelid margins stuck together in the morning, massive redness and swelling of the eyelid margins - indicated the presence of allergic conjunctivitis with accompanying inflammation of the eyelid margins $[1,2]$.

\section{Case report}

It is estimated that approximately $25 \%$ of the population is affected to a greater or lesser degree by eye allergy symptoms. Depending on the clinical picture and the pathophysiology of the disease, many forms of ocular allergic reactions can be distinguished. These include clinical forms of allergic conjunctivitis: acute, seasonal, chronic, spring; atopic keratoconjunctivitis, contact dermatitis of the eyelid and conjunctiva, giant cell conjunctivitis [2].

Eyelid margins inflammation is a condition that causes swelling and redness of the eyelids. It is one of the most common inflammatory eyelid conditions that is difficult to treat, often recurrent and tiresome for the patient [2]. The accompanying discomfort and irritation make it difficult to perform even basic daily activities - especially in the common chronic form [1]. In most of the observed cases both eyes are affected $[1,2]$.

The patient was treated with fludrocortisone $0.1 \%$ eye ointment 3 times a day for the first week, and twice a day in the following week. The drug contains fludrocortisone, a potent synthetic fluorinated glucocorticosteroid $(1 \mathrm{mg} / \mathrm{g}$ formulation) and is the only glucocorticosteroid available in the form of an ocular ointment.

The use of fludrocortisone $0.1 \%$ in the patient was aimed at rapid control and extinction of conjunctival and eyelid margin inflammation due to the strong anti-inflammatory effect of the active substance - fludrocortisone (a potent topical corticosteroid). Topical application of fludrocortisone $0.1 \%$, also reduces allergic reaction, has antipruritic and anti-edematous effects. It inhibits the production of exudate fluid in cases of inflammation of the anterior segment of the eye and after corneal and scleral injuries. Moreover, due to the form of the drug - eye ointment and its consistency, the contact time of the drug with the eyeball surface is prolonged up to about $2 \mathrm{~h}$ [3], which with an appropriate dosage significantly prolongs the preparation effect time and thus increases the therapeutic potential of the drug. The applied treatment proved to be effective - at the end of the first week of therapy the patient noticed a significant improvement, while in the second week all symptoms disappeared. 


\section{Case study 2}

A 40-year-old female patient presented to the ophthalmologist's office with chronic redness of the eyelid margins persisting with exacerbations and remissions for 2 months. The symptoms were most severe in the morning. The patient also complained of dry and burning eyes. On ophthalmologic examination, the patient was found to have numerous scales and discharge on the eyelashes (especially on the upper eyelids), significant congestion and redness of the eyelid margins, a ring-like swelling of the skin around the eyelashes, absence of some eyelashes, and small ulcerations on the lower eyelid margins (figures 1,2).

\section{FIGURE ( 1}

Hyperemia, redness of of the yelid margin, small ulcerations on the lower eyelid margin and absence of some eyelashes in the patient.

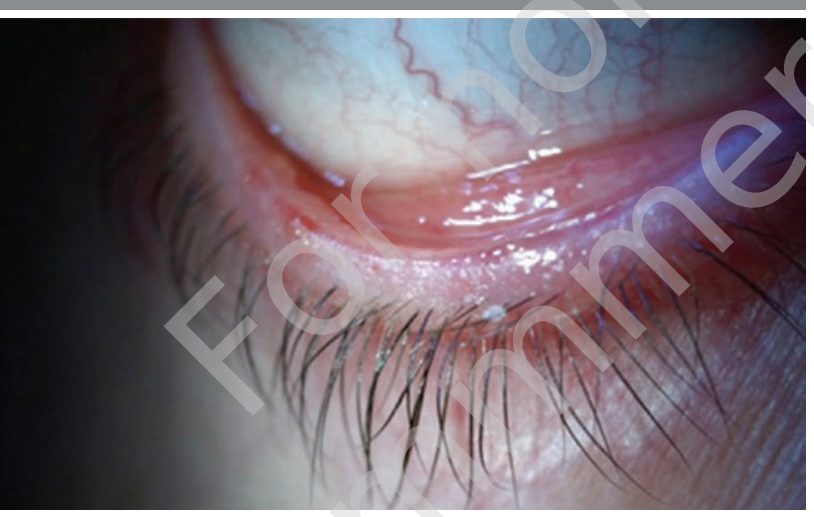

FIGURE ( 2

Multiple scales on the eyelashes of the upper eyelid and ring-like swelling of the skin around the eyelashes.

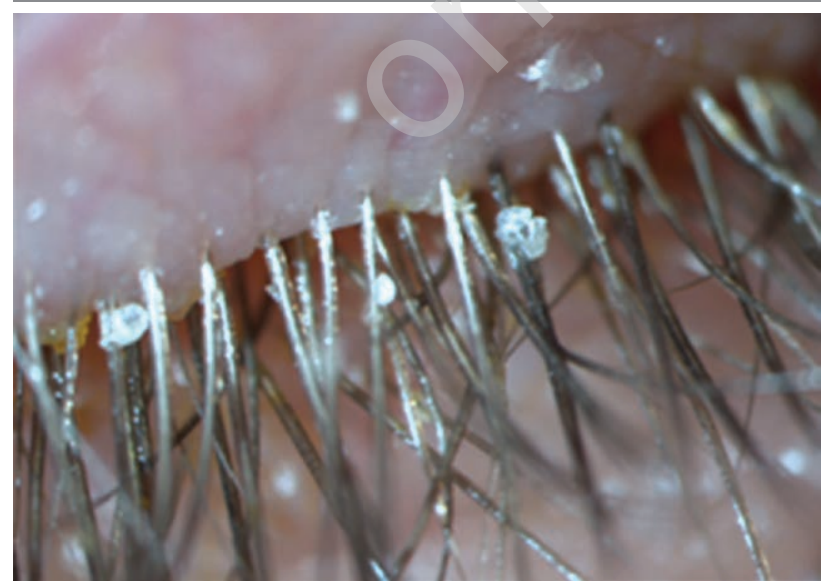

Slit-lamp examination did not reveal any corneal changes, while the BUT (break-up time) test showed a decrease in tear film break-up time to $5 \mathrm{~s}$ in the right eye and $6 \mathrm{~s}$ in the left eye. The clinical picture of the patient's eye changes was suggestive of anterior blepharitis [4, 5].
In addition to hygiene and heating of the eyelid margins, the patient was prescribed an eye ointment containing hydrocortisone + oxytetracycline 3 times a day to lubricate the eyelids with a spatula.

\section{Case report}

The patient's condition was caused by Staphylococcus aureus, a bacterium that frequently colonizes the skin of the eyelids. The mechanism of bacterial inflammatory action is complex. In addition to causing direct inflammation of the eyelid margins, the bacteria also release toxins and activate an excessive cellular immune response, which can cause the development of corneal lesions (epithelial defects, peripheral corneal infiltrates, corneal neovascularization). Occasionally, eyelid margin inflammation can cause the development of stye. Anterior eyelid margin inflammation usually occurs between the ages of 40 and 50 years and in $80 \%$ affects women [5].

The differential diagnosis should exclude Demodex, rosacea, atopic lesions of the eyelid skin, and psoriasis.

The treatment of anterior blepharitis is difficult, and the inflammation often recurs. It includes cleaning and massaging the eyelid margins to remove scales and discharge, warming the eyelids with various compresses and using antibiotics and corticosteroids. In the described patient, in addition to hygiene and warming the eyelid margins, an eye ointment containing hydrocortisone + oxytetracycline was prescribed 3 times a day to lubricate the eyelid margins with a spatula. The ointment provides a long contact with the eyelid margin, so that such preparations show a prolonged effect of the therapeutic substance. This provides a much more stable concentration of the drug compared to drugs in the form of aqueous solutions or even ocular suspensions. Oxytetracycline, which is one of the active ingredients in this formulation, is a broad-spectrum antibiotic that covers Gram(+) and Gram(-) bacteria, including penicillin-resistant strains, as well as atypical bacteria (Chlamydia spp. and Mycoplasma spp.). This antibiotic was introduced into treatment in 1950, but has been administered less frequently recently (we are now experiencing an "era" of aminoglycosides and fluoroquinolones in ophthalmology), so presumably bacterial resistance to this drug is not increasing as rapidly as to other antibiotics. Hydrocortisone contained in a topical ointment has anti-inflammatory, anti-exudative and antipruritic effects. Currently, in addition to the above-mentioned ointment, two ocular preparations in the form of ointment containing glucocorticosteroids and antibiotics are available in Poland. One of them contains dexamethasone and gentamicin, an antibiotic which is effective mainly in the treatment of Gram(-) infection. The other contains dexamethasone plus neomycin, which acts primarily on Gram(-) bacteria, and polymyxin B, which also acts primarily on Gram(-) bacteria, while Gram(+) bacteria show resistance to it. Therefore, an ointment containing hydrocortisone + oxytetracycline was chosen for the treatment of anterior eyelid 
margin inflammation in this patient, and artificial tear preparations were recommended.

\section{Case study 3}

In May 2019, a 24-year-old patient presented to the ophthalmologist's office complaining of bilateral persistent conjunctivitis symptoms for 4 weeks. Initially, such symptoms included medium redness (edema) of the eye, high ocular itchinf and relatively abundant serous secretion. They were accompanied by watery rhinitis and itching in the nose. As the patient was allergic to birch pollen, he recognized the allergy as the source of the symptoms and started using an OTC anti-allergy medication (cetirizine). After a week, an additional purulent discharge appeared, congealing the eyelids, especially in the morning. As a result, the patient went to an allergologist who ordered an ophthalmologic examination.

The ophthalmologic examination revealed ocular congestion, mucopurulent discharge, and conjunctival papular reaction. The cornea, anterior chamber, and posterior segment of the eyes remained normal

The initial symptoms (edema, itching, copious serous discharge, accompanied by a watery runny nose and nose itching) indicated allergic conjunctivitis. Since there was also purulent discharge, which is not a symptom of allergic inflammation, this suggested bacterial superinfection in the course of allergic conjunctivitis. The duration of the purulent discharge and the presence of papular conjunctival reaction could indicate chlamydial conjunctivitis, especially that the patient regularly attended a swimming pool $[6,7]$.

The patient was prescribed tri-component eye drops containing oxytetracycline, polymyxin $\mathrm{B}$, and hydrocortisone acetate ( 3 times daily for up to 2 weeks). These drops exhibit the combined effects of these ingredients. Oxytetracycline is a broad-spectrum antibiotic that acts on both $\operatorname{Gram}(+)$ and Gram(-) bacteria. Besides, it is one of the few drugs that act on chlamydia. Moreover, the drops contain polymyxin B, a polypeptide antibiotic with bactericidal activity primarily against Gram(-) bacteria. The third component of the drug is hydrocortisone, a synthetic glucocorticosteroid with anti-inflammatory and anti-allergic effects.

\section{CONCLUSIONS}

The majority of topical ophthalmic preparations available on the market are eye drops. Only isolated ophthalmic preparations are available as ointments and suspensions. Typically, these are drugs that have been long available on the market. As evidenced by the case reports presented above, they may continue to be an effective form of therapy for conjunctival inflammation.

Figures: from the author's own materials.

\section{CORRESPONDENCE}

Beata Rymgayłło-Jankowska, MD, PhD

Department of Diagnostic and Microsurgery of Glaucoma,

Chair of Ophthalmology, Medical University of Lublin

20-079 Lublin, ul. Chmielna 1

e-mail: beatar@am.lublin.pl

\section{ORCID}

Marek E. Prost - ID - http://orcid.org/0000-0002-5620-4171

Beata Rymgayłło-Jankowska - ID - http://orcid.org/0000-0001-6502-5397

\section{References}

1. Bowling B. Kansky. Okulistyka kliniczna. Ed. 8. Edra Urban \& Partner, Wrocław 2017.

2. Szaflik J, Izdebska J. Choroby aparatu ochronnego oka. BCSC 8, Seria Basic and Clinical Science Course. Edra Urban \& Partner, Wrocław 2019.

3. Prost M, Jachowicz R, Nowak J. Kliniczna farmakologia okulistyczna. Elsevier Urban \& Partner sp. z o.o., Wrocław 2013.

4. Malukiewicz G. Choroby powiek. In: Prost M, Jachowicz R, Nowak JZ. Kliniczna farmakologia okulistyczna. Edra Urban \& Parter, Wrocław 2016.

5. American Academy of Ophthalmology: Blepharitis preferred practice pattern. https://www.aao.org/preferred-practice-pattern/ blepharitis-ppp-2018 (access: 15.12.2021).

6. Prost M. Bakteryjne zapalenie spojówki i rogówki - wytyczne terapeutyczne. OphthaTherapy. 2018; 5(suppl 1): 5-9.

7. Prost M. Chlamydiowe zapalenie spojówki i rogówki - wytyczne terapeutyczne. OphthaTherapy. 2018; 5(suppl 1): 18-20.

Authors' contributions:

Marek E. Prost: 70\%; Beata Rymgayłło-Jankowska: 30\%.

Conflict of interest:

None.

Financial support:

None.

Ethics:

The content presented in the article complies with the principles of the Helsinki

Declaration, EU directives and harmonized requirements for biomedical journals. 